\title{
Effect of Seasonal Variations, Altitude and Geographical Location on the Onset of Dawn Chorus in Three Bird Species in Middle East
}

\author{
Nail M. Hasan ${ }^{*}$ \\ Department of Biology and Biochemistry, Birzeit University, P.O. Box 14, Palestine
}

\begin{abstract}
One of the behavioral aspects of passerine birds is their dawn chorus. Therefore the onset of dawn chorus in three bird species (blackbirds, bulbuls and house sparrows) was investigated in different seasons, years and geographical locations with varying temperature range and altitude. Results show that the onset of dawn chorus varied for the different seasons of the year but was similar from year to year and was not affected by varying geographical locations with different altitude and climate. Results also show that different bird species start singing independently of each other. This is the first time that such parameters are investigated for any bird species.
\end{abstract}

Keywords: Dawn chorus, geographical location, altitude, seasonal variations.

\section{INTRODUCTION}

Dawn singing is an important behavioral feature of songbirds and has many implications for humans such as giving insights into learning, speech and memory [1, 2]. There are several functions of birdsong. The two main functions are territory defense and mate attraction [3]. In the wild animals rely on the cycling of the sun and the seasons to adjust their biological clocks and metabolism according to the photoperiod [4]. Therefore this kind of primary investigation is very important.

Timing and patterns of dawn chorus are parts of bird behavior that are controlled by many factors. Eye-size and foraging height are believed to be determinant factors $[5,6]$. There are other factors affecting the timing and intensity of the dawn chorus. It was demonstrated [7] that the nutritional state and the mate fertility status affect dawn chorus. It is suggested by several studies that behavioral measures can be more comprehensive than other biomarkers in indicating an organism's health and welfare [8]. Therefore any physiological stress will affect singing output. It was proven that noise and light pollution and other environmental (heavy metals) pollutants affect the timing and pattern of dawn singing in song birds [9-13].

Climate conditions and geographical location are also shown to influence singing behavior. Researchers [14] show that difference in song patterns among the many species of mockingbird vary with climate in the diverse places they live. Specifically, species that are subject to more variable and unpredictable climates also have more impressive singing skills. Their data showed that mockingbirds living in more demanding environments tend to have more elaborated song displays. Therefore it is thought that singing behavior also tells a lot about the singer.

*Address correspondence to this author at the Department of Biology and Biochemistry, Birzeit University, P.O. Box 14, Palestine; Tel: 009661 2520088, Ext. 47269; Mobile: 00966558436180 ;

E-mail: nhasan@birzeit.edu
Sine climate conditions, environmental factors and pollutants can affect the timing and pattern of dawn chorus $[10,11,15]$ the timing and patterns of dawn chorus can be used as markers / indicators of climate change and other environmental factors (i.e. pollution).

Knowing from previous literature that many climatic and environmental factors affect dawn chorus, it is expected that the start of dawn chorus could differ in two sites which are so different as regards altitude and temperature so was decided to investigate the effect of different seasons of the year, different geographical locations of varying temperature and altitude on the onset of dawn chorus.

\section{METHODS}

The three birds that were investigated in this study are the main passerine birds that inhabit our region and live in close proximity to humans all year round, not migratory birds. Off course other bird species existed but in small numbers and cannot be observed on daily basis. This is an observational study of the onset of dawn chorus of the following species: White-spectacled and Black-headed, yellow-vented Bulbuls (Pycnonotus xanthopygos and barbatus), blackbirds (Turdus merula) and house sparrows (Passer domesticus). These birds start their breeding season in spring (March-April) and live free in their natural habitat without any intended human interference.

The timing of the start of dawn singing was monitored all year round from the top roof of a house on top of a small hill in a quiet residential area in the south east outskirts of Tulkarem city, West Bank, Palestine (coordinates: $32^{\circ} 18^{\prime} 41.50^{\prime \prime} \mathrm{N} 35^{\circ} 01^{\prime} 37.34^{\prime \prime} \mathrm{E}$. Altitude: $130 \mathrm{~m}$ above sea level) and it has a Mediterranean climate. This location allowed the monitoring of an area of at least 150 meters in diameter and was recorded on a calendar that shows the daily sunrise / sunset. This is a very quiet location with scattered houses that have large gardens, and there are no main roads and no heavy traffic. 
The other location that was investigated is a very quiet place in the village of Sheikh Husain in the Jordan Valley; Jordan (coordinates: $32^{\circ} 27^{\prime} 27^{\prime \prime} \mathrm{N}, \quad 35^{\circ} 33^{\prime} 21.96^{\prime \prime} \mathrm{E}$. Altitude: $300 \mathrm{~m}$ below sea level) and has a subtropical climate. Jordan valley is the lowest place on earth. Spring/summer temperatures at this location are usually around 10 degrees above that in Tulkarem city. Arial distance between these two location is about $100 \mathrm{Km}$.

Birdsong monitoring started at least 2 hours before sunrise at the time of the first call for Muslims dawn prayer. The call for actual dawn prayer is about 85 minutes before sunrise.

\section{Criteria of Recording the Start of Dawn Chorus}

There has to be more than one incidence of continued singing followed by other birds at another position to be considered as true start of singing thus avoiding any accidental singing. Exact number of birds involved in singing is not determined but birds from the same species are noted to join the first song within few minutes. It has to be said here that, at this location, the first song was always followed by others within few minutes.

\section{Statistics}

Because the variables tested were not normally distributed (using Shapiro-Wilks test), nonparametric tests were used to compare singing times for the different birds (Wilcoxon matched pairs test when comparing two groups of birds and the Friedman test for comparing three groups).

\section{RESULTS}

Table 1 shows the average time (minutes) of the start of singing before sunrise for bulbuls, blackbirds and sparrows consecutively from January until September 2009. The months of October, November and December 2008 were determined in a previous study [16]. This table shows that each bird species has its own set of dawn singing and is apparently independent of other species, meaning that the start of dawn singing of one species is not affected directly by the other species (i.e. the gap between them is large). The table also shows that the start of dawn singing tends to be classified in two main sets: spring/summer where singing is early and autumn/winter where singing is late compared to sunrise.

Fig. (1) shows a comparison of the average time for the start of dawn singing before sunrise for the three bird species investigated over 9 months of the year. The figure does not indicate any cross or direct relationship between the three species investigated (i.e. singing of one species does not cause the singing of other species). It shows that blackbirds started singing much earlier than the other two species. Bulbuls were next in singing but sparrows can sing

Table 1. Average Time (minutes) and Standard Deviation of Start of Singing before Sunrise for the Three Bird Species Studied in Tulkarem $(* *$ not detected)

\begin{tabular}{|c|c|c|c|c|c|c|}
\hline \multirow[b]{2}{*}{ Month } & \multicolumn{2}{|c|}{ Bulbul } & \multicolumn{2}{|c|}{ Blackbird } & \multicolumn{2}{|c|}{ Sparrow } \\
\hline & Average & STDEV & Average & STDEV & Average & STDEV \\
\hline Jan-09 & 17.94 & 2.341 & 35.81 & 3.87 & 13.64 & 2.158 \\
\hline Feb-09 & 15.71 & 3.379 & 51.29 & 11.499 & 16.526 & 3.454 \\
\hline Mar-09 & 24.89 & 4.846 & 52.61 & 9.708 & 31.217 & 8.676 \\
\hline Apr-09 & 26.86 & 2.274 & 67.57 & 15.926 & 32.478 & 5.177 \\
\hline Jun-09 & 32.31 & 2.451 & 51.17 & 7.833 & 30.448 & 3.869 \\
\hline Jul-09 & 31.24 & 1.994 & 51.85 & 10.615 & 23.207 & 4.916 \\
\hline Aug-09 & 29.07 & 2.970 & $* *$ & $* *$ & 15.333 & 3.763 \\
\hline Sep-09 & 25.25 & 1.689 & 35.810 & 4.025 & 14.538 & 1.923 \\
\hline Dec-08 & 17.26 & 3.445 & 25.000 & 6.391 & 14.112 & 1.654 \\
\hline
\end{tabular}

Friedman ANOVA and Kendall Coeff. of Concordance (Spreadsheet17) ANOVA Chi Sqr. $(\mathrm{N}=12, \mathrm{df}=2)=18.66667 \mathbf{p}=\mathbf{0 . 0 0 0 0 9}$ Coeff. of Concordance $=0.77778$ Aver. rank $\mathrm{r}=$ 0.75758 .

\begin{tabular}{|c|c|c|c|c|}
\multicolumn{5}{c}{ Descriptive Statistics (Spreadsheet Table 1) } \\
\hline & Valid N & Median & Lower - Quartile & Upper - Quartile \\
\hline Sparrows & 12 & 16.54357 & 14.32423 & 29.98220 \\
\hline Bulbul & 12 & 25.06731 & 19.75774 & 29.00222 \\
\hline Blackbird & 12 & 45.57971 & 34.64000 & 52.23027 \\
\hline
\end{tabular}


sometimes before bulbuls indicating the independent relationship between them. As shown on Table 1, these differences were found to be statistically significant $(\mathrm{P}=0.00009)$. The figure also shows that birds started singing earlier in spring / summer months. This might be explained by starting of breeding season. No explanation for why blackbirds sing much earlier than other birds.

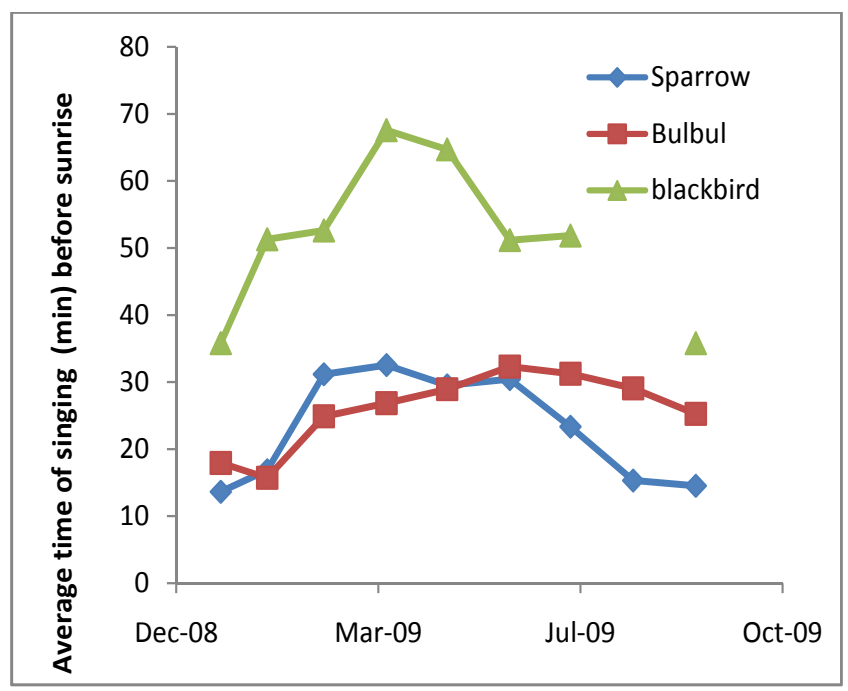

Fig. (1). Average time (min) of onset of dawn singing before sunrise for 3 bird species versus the month of the year.

Looking at average values for each month and their standard deviations it can be concluded that bulbuls are a good model to be used for future studies on any factor that affects the timing of dawn chorus (variations of the onset of onset of singing is the smallest of all).

Table 2 shows bulbul and sparrow data for Sheikh Husain village (Jordan) for August 2010 compared to Tulkarem area (Palestine) on the same month. It is obvious from this data that geographical location, altitude and increasing temperatures had no significant effect $(p=0.17$ and 0.053 for bulbuls and sparrows respectively) on the onset of dawn chorus for these two bird species in these two locations.

Recent data obtained for bulbuls, blackbirds and sparrows for the month of July and August 2011 is very similar to previous data.

\section{DISCUSSION}

This investigation shows that bulbuls and sparrows sing all year round while blackbirds stopped singing around and during the month of August. This is in agreement with information on the web [17] but no real explanation to why this is the case. It can be assumed that the temperature around the month of August might be too hot for blackbirds to sing. Results show that there are seasonal variations in the onset of dawn chorus in the same species. In general, results show that birds started singing earlier in spring/summer than autumn/winter months when compared to sunrise. This is probably due to internal factors such as social (breeding / mating) and nutritional status and external factors such as ambient temperature and availability of food. Most of the published work had shown that the above mentioned factors affect the pattern and output of singing but the timing of dawn chorus was not investigated. Armstrong [18] reviewed the relationship of bird song to weather and noted that low temperatures and mist were especially significant in retarding song output. It was also shown by O'Connor and Hicks [19] that temperature is of great importance in determining song output and that warmer temperatures had increased the singing output.

Will increasing temperatures make birds sing earlier or during nights? Environmental factors such as noise and light pollution have been shown to make birds sing earlier and at night $[10,11]$. It is still has to be proven that increasing weather temperatures can cause an early onset of dawn chorus. Our findings (Table 2) show that increasing temperatures had no effect on dawn chorus and its timing for bulbuls and sparrows. This true for these two locations only but we can not generalize on all locations. Further investigations that include many other different locations of these variables is needed. Unlike bulbuls, blackbirds might prefer a cooler climate (i.e. blackbirds can be found in cooler climates (UK) but not bulbuls) hence not singing during August. Climate change is suspected as the cause of dwindling bird populations and migration to a better climate [20].

These data also show that the time of first song is species-specific and is independent of other species (i.e. they did not follow each other in singing; each species has its own independent start). It was demonstrated [6] that the time of first song is a species-specific trait across 57 species investigated. They also showed that time of first song is not affected by site or date which is in agreement with our results.

Therefore it is expected that the same bird species will start singing almost at the same time for consecutive years. This is off course not conclusive but our study confirms that bulbuls and sparrows started singing at similar times when comparing August 2009 to August 2010. Recent data on August 2011 is the same as the previous two years.

It is also very interesting to see that the same bird species sing at the same time at two different geographical locations with varying temperature range and altitude. There are no reports in the literature on the effect of altitude on birdsong (pattern, output or timing). This is the first time that such a comparison is made.

This makes these data a valuable source for coming years for people who are interested in dawn singing and climate change (increasing temperatures), pollution (light and noise) and other environmental factors. These results also support the notion that bulbuls are the better model for studying effect of environmental factors on birdsong (i.e. they sang at the same time every day with little variations).

In one of the models designed to study bird dawn singing, Hutchinson [21] predicted that from day to day cloud cover determines when a dawn chorus starts, but that overnight temperature and wind strength have more effect on chorus intensity and duration. It has to be seen whether birds 
Table 2. Comparison of Two Geographical Locations of Varying Climates and Altitude for the Month of August 2010

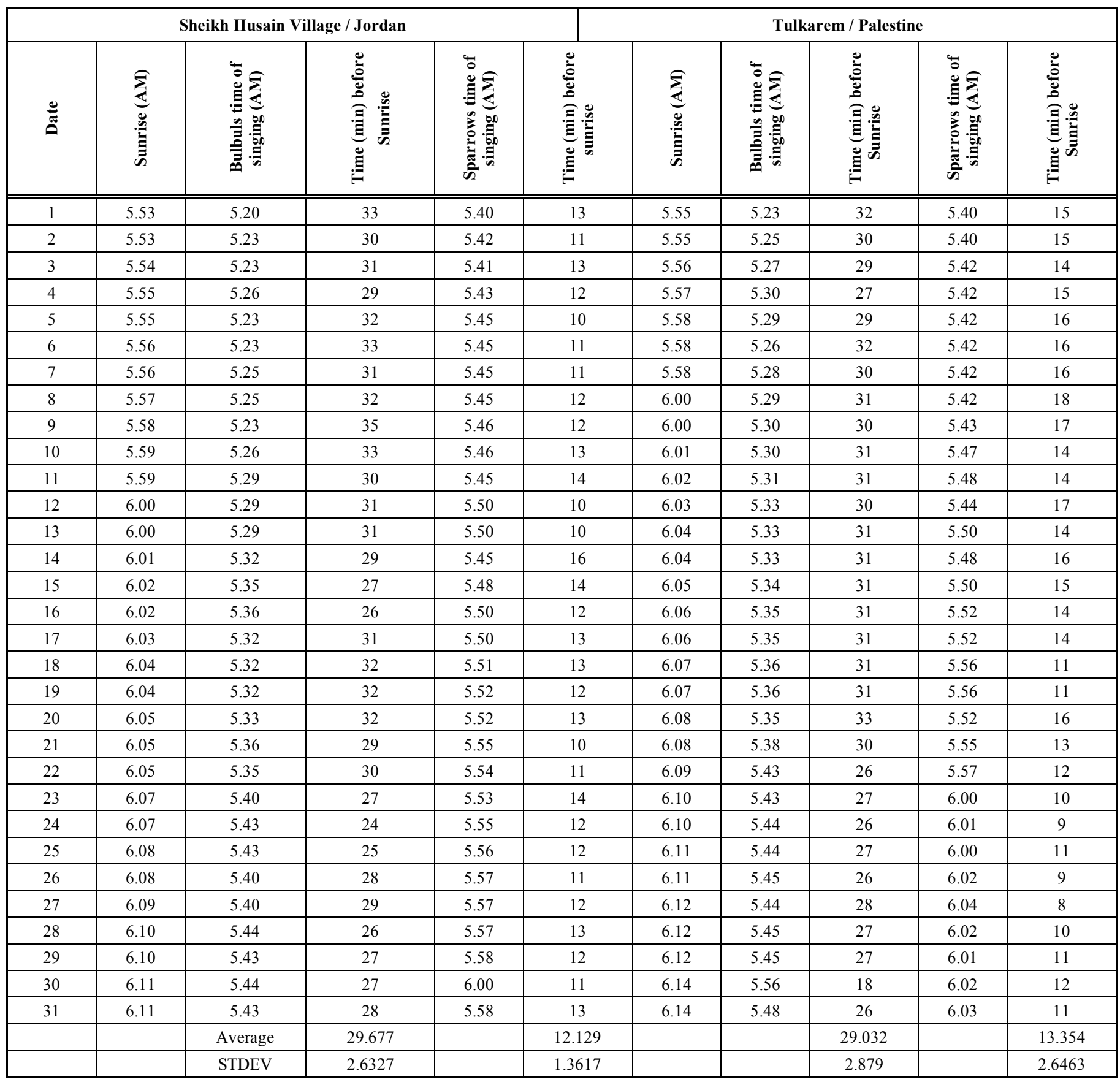

Wilcoxon Matched Pairs Test (Bulbul P vs. J) Marked tests are significant at $\mathrm{p}<0.05000$

\begin{tabular}{|l|c|c|c|c|}
\hline & Valid - N & T & $\mathbf{Z}$ & p-value \\
\hline bulbul-J and bulbul-P & 26 & 122.5000 & 1.346093 & 0.178274 \\
\hline
\end{tabular}

Descriptive Statistics

\begin{tabular}{|c|c|c|c|c|}
\hline & Valid N & Median & Lower - Quartile & Upper - Quartile \\
\hline bulbul-P & 31 & 30.00000 & 27.00000 & 32.000 \\
\hline bulbul-J & 31 & 30.00000 & 27.00000 & 31.000 \\
\hline
\end{tabular}

living in hotter climates (desert conditions) or equatorial climates sing in a similar manner to this study.
Wilcoxon Matched Pairs Test (Sparrow) Marked tests are significant at $\mathrm{p}<0.05000$

\begin{tabular}{|c|c|c|c|c|}
\hline & Valid - N & T & $\mathbf{Z}$ & p-value \\
\hline sparrow J and sparrow P & 29 & 128.00 & 1.9353 & 0.053 \\
\hline
\end{tabular}

Descriptive Statistics (Sparrow J vs. P)

\begin{tabular}{|c|c|c|c|c|}
\hline & Valid N & Median & Lower - Quartile & Upper - Quartile \\
\hline sparrow J & 31 & 12.000 & 11.000 & 13.000 \\
\hline sparrow P & 31 & 14.000 & 11.000 & 16.000 \\
\hline
\end{tabular}

Therefore this data can serve as a record for future researches who are interested in the effect of climate change, 
other environmental factors and pollution (noise, light, heavy metals) on the onset of birdsong. It also supports a previous suggestion that bulbuls are the most suited model for these studies.

\section{ACKNOWLEDGEMENT}

The author wishes to thank Dr. Motasim Badri (Biostatistician) from Department of Basic Sciences/ KSAUI-HS for his great assistance in conducting biostatistical tests for this study.

\section{CONFLICT OF INTEREST}

None Declare.

\section{REFERENCES}

[1] Bolhius JJ, Gahr M. Neuronal mechanisms of bird song memory. Nat Rev Neurosci 2006; 7: 347-57.

[2] Penn State. Song birds yield insight into speech production. Sci Daily 2010.

[3] Brunne P, Pasinelli G. Variation in singing style use in the reed bunting Emberiza schoeniclus: influencing factors and possible functions. J Avian Biol 2010; 41(4): 388-97.

[4] Thrush PR. Lighting and your bird. NCS J 1999; XVI, No. 4.

[5] Thomas RJ, Sze'kely T, Cuthill IC, et al. Eye size in birds and the timing of song at dawn. Proc R Soc Lond 2002; B 269: 831-7.

[6] Berg KS, Brumfield RT, Apanius V. Phylogenetic and ecological determinants of the Neotropical dawn chorus. Proc Royal Soc 2006; B 273(1589): 999-1005.
[7] Cuthill CI, MacDonald WE. Experimental manipulation of dawn and dusk chorus in blackbird Terdus merula. Behav Ecol Sociobiol 1990; 26: 209-16.

[8] DeWan A, Dubois N, Theoharides K, Boshoven J. Understanding the impacts of climate change on fish and wildlife in North Carolina. Defenders of Wildlife 2010, Washington, DC.

[9] Gorisson L, Snoeijs T, Eens EV. Heavy metal pollution affects dawn singing behavior in a small passerine bird. Oecologia 2005; 145: 504-9.

[10] Fuller RA, Warren PH, Gaston KJ. Daytime noise predicts nocturnal singing in urban robins. Biol Lett 2007; 3: 368-70.

[11] Miller MW. Apparent effects of light pollution on singing behavior of American robins. Condor 2006; 108 (1): 130-9.

[12] Wood WE, Yezerinac SM. Song Sparrow (Melospiza melodia) varies with urban noise. Auk 2006; 123(3): 650-9.

[13] Nemeth E, Brumm H. Blackbirds sing higher-pitched songs in cities: adaptation to habitat acoustics or side-effect of urbanization? Anim Behav 2009; 78(3): 637-41.

[14] Botero CA, Boogert N, Lovette IJ, Vehrencamp SL. Climatic patterns predict the elaboration of song displays in mockingbirds. Curr Biol 2009; 19: 1-5.

[15] Otter K, Chruszz B, Ratcliffe L. Honest advertisement and song output during dawn chorus of black-capped chickadees. Behav Ecol 1997; 8(2): 167-73

[16] Hasan NM. The effect of environmental conditions on the start of dawn singing of blackbirds and bulbuls. Jordan J Biol Sci 2010; 3(1): 13-6.

[17] http://www.wildengland.com/wild-animals/resident-birds/songbirds

[18] Armstrong EA. A Study of Bird Song 1963. Oxford.

[19] O'Connor RJ, Roger KH. The influence of weather conditions on the detection of birds during Common Birds Census fieldwork. Bird Stud 1980; 27(3): 137-51

[20] Walker M. Climate change 'makes birds shrink' in North America. Earth News 2010.

[21] Hutchinson JMC. Two explanations of the dawn chorus compared: How monotonically changing light levels favor a short break from singing. Anim Behav 2002; 64(4): 527-39. 